\title{
Caracterização morfológica e frequência dos estádios do ciclo do epitélio seminífero em preás (Galea spixii Wagler, 1831) criados em cativeiro ${ }^{1}$
}

\author{
Paulo R.S. Santos ${ }^{2 *}$, Tássia V.B. Carrara ${ }^{3}$, Luana Célia S. Silva² ${ }^{2}$ Alexandre R. Silva ${ }^{4}$, \\ Moacir F. Oliveira ${ }^{4}$ e Antônio C. Assis Neto ${ }^{5}$
}

\begin{abstract}
Santos P.R.S., Carrara T.V.B., Silva L.C.S., Silva A.R., Oliveira M.F. \& Assis Neto A.C. 2011. [Morphological characterization and frenquency of stages of the seminiferous epithelium cycle in captive bred Spix's Yellow-Toothed (Galea spixii Wagler, 1831).] Caracterização morfológica e frequência dos estádios do ciclo do epitélio seminifero em preás (Galea spixii, Wagler 1831) criados em cativeiro. Pesquisa Veterinária Brasileira 31(Supl.1): 18-24. Departamento de Cirurgia, Faculdade de Medicina Veterinária e Zootecnia, Universidade de São Paulo, Av. Prof. Dr. Orlando Marques de Paiva 87, São Paulo, SP 05508-270, Brazil. E-mail: pauloramos@usp.br

Studies based on the testicular characteristics are strongly associated with the reproductive efficiency of various species. Thus, the developed project aimed to identify the cells of the seminiferous epithelium, histologically characterized their associations, which form stages, and determine the frequency of these. The fragments of testes, 30, 45, 60, $75,90,105,120,150$ days were collected Multiplication Center of Universidade Federal Rural do Semi-Árido, Mossoró, RN. Through the process of fixing, washing in solutions of increasing concentrations of alcohols (70-100\%), dehydration in xylene, inclusion in Histosec $®$, preparation of histological slides, stained with hematoxylin and eosin (HE) and their photomicrographs for the characterization of cell nuclei of the germinal epithelium and the definition of the eight stages of the seminiferous epithelium cycle (CES) based on the tubular morphology method. The different age groups all animals at 90 to 150 days of age showed all stages of the CES. Stages I and III showed the highest and lowest frequency, respectively. Animals categorized as prepubertal (30 days), pubertal (45 to 90 days old) and postpubertal (105 to 150 days of age) had stage I, IV and VIII with a higher frequency, respectively.
\end{abstract}

INDEX TERMS: Rodent, testis, germ epithelium cells, spermatogenesis.

\footnotetext{
${ }^{1}$ Recebido em 27 de julho de 2011.

Aceito para publicação em 3 de novembro de 2011.

${ }^{2}$ Departamento de Cirurgia, Setor Anatomia, Programa de Pós-Graduação em Anatomia dos Animais Domésticos e Silvestres, Faculdade de Medicina Veterinária e Zootecnia (FMVZ), Universidade de São Paulo (USP), Av. Prof. Dr. Orlando Marques de Paiva 87, Cidade Universitária, São Paulo, SP 05508 270, Brasil.*Autor para correspondência: pauloramos@usp.br

${ }^{3}$ Faculdade de Zootecnia, Universidade Estadual Paulista "Júlio de Mesquita Filho" (Unesp), Campus de Dracena, Rodov. Cmte. João Ribeiro de Barros, SP 294 Km 651, Dracena, SP 17900-000, Brasil.

${ }^{4}$ Departamento de Ciências Animais, Universidade Federal Rural do Semi Árido (UFERSA), Campus Central, BR110 Km 47, Mossoró, RN 59625-900, Brasil..

${ }^{5}$ Departamento de Cirurgia, Setor Anatomia, Faculdade de Medicina Veterinária e Zootecnia (FMVZ), Universidade de São Paulo (USP), Av. Prof. Dr. Orlando Marques de Paiva 87, Cidade Universitária, São Paulo, SP 05508-270, Brasil.
}

RESUMO.- Estudos baseados nas características testiculares estão altamente relacionados com a eficiência reprodutiva de varias espécies. Assim, o projeto desenvolvido teve como objetivo identificar as células do epitélio seminífero, caracterizar histologicamente suas associações, que formam os estádios, e determinar a frequência destes. Os fragmentos de testículos, com 30, 45, 60, 75, 90, 105, 120, 150 dias foram coletados no Centro de Multiplicação da Universidade Federal Rural do Semi-árido, Mossoró/ RN. Passando pelos processos de fixação, lavagens em soluções de concentrações crescentes de álcoois (70-100\%), desidratação em xilol, inclusão em Histosec ${ }^{\circledR}$, preparação das lâminas histológicas, colorações em Hematoxilina e Eosina (HE) e suas fotomicrografias para a caracterização dos núcleos celulares do epitélio germinativo e a definição dos 
oitos estágios do ciclo do epitélio seminífero (CES) baseados no Método da Morfologia Tubular. Das faixas etárias analisadas todos os animais de 90-150 dias de idade apresentaram todos os estádios do CES. Os estádios I e III foram os que apresentaram maior e menor freqüência, respectivamente. Os animais caracterizados como pré-púberes $(30$ dias), púberes (45-90 dias de idade) e pós-púberes (105150 dias de idade) apresentaram os estádios I, VIII e IV com uma maior freqüência, respectivamente.

TERMO DE INDEXAÇÃO: Roedores, testículo, células do epitélio germinativo, espermatogênese.

\section{INTRODUÇÃO}

0 preá do semiárido nordestino (Galea spixii, Wagler 1831) é um roedor pertencente à família Caviidae, subordem Hystricognathi, subfamília Caviinae, sendo encontrados nas regiões da Caatinga e do Cerrado Brasileiro (Reis et al. 2006, Oliveira et al. 2008, Oliveira et al. 2010). Possui cauda curta e uma pelagem densa com coloração do dorso que varia de acinzentada a amarelada, apresentando um anel de pêlos brancos ao redor dos olhos (Reis et al. 2006). É um animal terrestre e de hábito crepuscular, vivendo em bandos e alimentando-se de folhas (Mendes 1987). Possui comprimento de $22,5-23,5 \mathrm{~cm}$ e apresenta uma massa corpórea de 375-405 gramas (Oliveira et. al. 2008). É um animal que se reproduz ao longo do ano, apresentando um período de gestação de 48 dias, podendo ocorrer de seis a sete ninhadas por ano sendo a mesma formada, em média, por 2 a 4 crias (Eisenberg \& Redford 1999, Reis et al. 2006, Oliveira et. al. 2008). Em machos, o estudo de diversas etapas do desenvolvimento testicular, especialmente daquelas associadas à puberdade e a maturidade sexual, é de suma importância para a entrada da atividade sexual do animal (França 1988).

Nos túbulos seminíferos de animais sexualmente maduros, as células espermatogênicas não estão arranjadas ao acaso, mas sim organizadas numa série bem definida de associações celulares ou estádios, os quais se sucedem numa determinada área do epitélio germinativo, com o decorrer do processo espermatogênico. Tal sequência ordenada constitui o processo denominado de ciclo do epitélio seminífero (CES) (Leblond \& Clermont 1952, Ortavant et al. 1977, Russel et al. 1990). A identificação dos estádios do CES é essencial para estudos quantitativos do testículo e para o entendimento de como a espermatogênese é regulada (Roosen-Runge \& Geisel Jr 1950, Leblond \& Clermont 1952, França \& Russell 1998).

Na maioria das espécies de mamíferos, o arranjo dos estádios é segmentar e usualmente existe somente um único estádio por secção transversal de túbulo seminífero (Leblond \& Clermont 1952, Russell et al. 1990). Contudo, em alguns primatas, um arranjo helicoidal é observado, no qual dois ou mais estádios estão presentes por secção transversal tubular (Heller \& Clermont 1964, Sharpe 1994, Smithwick et al. 1996).

Estudos morfológicos do sistema reprodutor masculino que indiquem as condições do epitélio germinativo são essenciais para o reconhecimento dos estágios de maturação sexual em que se encontram os indivíduos (Licht \& Gorman 1970). Dentre os sistemas utilizados para se estudar os estádios do CES, o mais empregado é aquele baseado na forma e na localização dos núcleos das espermátides e na presença de figuras de divisões meióticas (Roosen-Runge \& Geisel Jr 1950, Courot et al. 1970, Guerra 1983, França 1991). Este sistema, designado como método da morfologia tubular descrito por Berndtson (1977), permite a obtenção de oito estádios do ciclo para a maioria das espécies estudadas.

Assim, torna-se necessário o desenvolvimento de estudos nesta área, os quais contribuiriam de maneira significativa para a compreensão da biologia reprodutiva dos preás, uma vez que o sucesso evolutivo que determina a perpetuação de uma espécie e suas relações com o ecossistema se deve à sua reprodução. Portanto, o objetivo deste estudo foi identificar as células da linhagem espermatogênica, associar e caracterizar os oito estádios do ciclo do epitélio seminífero e estabelecer as frequências relativas dos estádios do CES.

\section{MATERIAL E MÉTODOS}

Fragmentos de testículos nas idades 30, 45, 60, 75, 90, 105, 120, 150 dias foram coletados no Centro de Multiplicação da Universidade Federal Rural do Semiárido, Mossoró/RN (Autorização IBAMA no2028236/2008). Processo Comitê de Ética: 009/2008.

Colheita do testículo. Os testículos dos animais de 30 a 150 dias de idade foram colhidos através de orquiectomias e em seguida os mesmos foram pesados. Durante o procedimento cirúrgico, os animais de 60 a 150 dias foram anestesiados com 0,025mg/ $\mathrm{ml} / \mathrm{SC}$ de sulfato de atropina e $0,2 \mathrm{ml} / \mathrm{kg} / \mathrm{IM}$ de Zoletil. Os demais animais, de 30 e 45 dias, também foram anestesiados com o mesmo protocolo, mas em seguida foram sacrificados tendo em vista a dificuldade de se encontrar os pequenos testículos dentro da cavidade abdominal. Após as orquiectomias, cada testículo foi separado do respectivo epidídimo e em seguida obtido sua massa e comprimento. Para a obtenção da massa ( $g$ ) utilizou-se uma balança analítica (Modelo: Kern 430-21 Max 50g d=0,001g) e, para a mensuração do comprimento foi utilizado um paquímetro inoxidável com divisões em milímetros (Vernier Caliper 4-way measurement, $150 \mathrm{~mm} \times 0,02 \mathrm{~mm}$ ).

Processamento histológico. Posteriormente os testículos de cada animal foram acondicionados em solução de Bouin, Paraformaldeído e Glutaraldeído por um período de 24 horas. Depois de desidratados, pela passagem em álcoois de concentrações crescentes (70 a 100\%) e diafanizados em xilol, foram incluídos em parafina (Luna 1968). Efetuou-se então cortes de $5 \mu \mathrm{m}$ de espessura em Micrótomo (Modelo Leica RM 2145) os quais foram corados por Hematoxilina e Eosina (HE). As lâminas foram analisadas por microscópio de luz (Modelo Leica DM 2500) e utilizadas para descrições microscópicas dos órgãos.

Identificação dos tipos celulares do epitélio seminífero. Foram identificadas as células da linhagem espermatogênica em 200 secções transversais, sempre considerando as secções mais circulares, para cada testículo, sendo então associados e estabelecidos os oito estádios do ciclo do epitélio seminífero (CES).

Caracterização dos estádios do ciclo do epitélio seminífero. 0 ciclo do epitélio seminífero foi caracterizado pelo método da morfologia tubular, que se baseia nas alterações de forma e posição do núcleo das células espermatogênicas e na ocorrência de suas divisões meióticas no epitélio seminífero (Curtis 1918, Roosen-Runge \& Geisel Jr 1950, Swierstra 1968, Courot et al. 1970, 
Amann \& Schanbacher 1983), permitindo assim a obtenção de oito estádios do ciclo.

Frequência relativa dos estádios do ciclo do epitélio seminífero. As frequências relativas dos estádios do ciclo do epitélio seminífero foram determinadas pelo exame e classificação de 200 secções transversais de túbulo seminífero, escolhidos ao acaso, percorrendo-se os cortes em varredura horizontal. 0 cálculo das frequências, expressas em porcentagem, foi feito para os animais de idades entre 90 e 150 dias (onde em todas as secções foi possível observar todos os estádios do ciclo do epitélio seminífero); de acordo com a fase do desenvolvimento sexual (pré-púberes, púberes e pós-púberes); e analisando individualmente cada animal por idade.

Analise estatística. Foram realizadas análises descritivas de média e desvio padrão através do programa GraphPad Prism4 para os parâmetros testiculares.

\section{Morfologia das células espermatogênicas}

RESULTADOS

0 ciclo do epitélio seminífero é divido em oito estádios, mostrados na figuras 1. Para caracterizá-los é necessário identificar, através do método da morfologia nuclear, os tipos celulares da linhagem espermatogênica e células de Sertoli. No preá (Galea spixii) foram identificadas as seguintes células da linhagem espermatogênica: espermatogônias do tipo A, espermatócitos primários (pré-leptóteno/ leptóteno, paquíteno, diplóteno, zigóteno), espermatócitos secundários, espermátides arredondadas, espermátides alongadas e as células de Sertoli.

A espermatogônia do tipo A foi identificada por estar presente na membrana basal do epitélio seminífero. Tendo como características sua forma arredonda e grande, presença de um núcleo com uma textura lisa levemente corada e o nucléolo evidente, geralmente esférico (Fig.1.II). Os espermatócitos primários em pré-leptóteno/leptóteno se encontravam próximos à membrana basal, apresentando uma forma compacta e uma fina borda do citoplasma envolvendo o núcleo (Fig.1.I). Os espermatócitos primários em zigóteno continham uma forte expressão de uma massa compacta de cromossomos centralmente localizados em um dos lados do núcleo, mostrando um formato de semi-lua (Fig.1.III). Os espermatócitos primários em paquíteno apresentaram um núcleo redondo onde os cordões de cromatina mostravam-se bem corados e dissociados (Fig.1.I). Os espermatócitos primários em diplóteno apresentaram um maior núcleo e com uma maior dissociação dos cromossomos, encontrando-se mais afastado da membrana basal do epitélio (Fig.1.III). Os espermatócitos secundários encontravam-se associados com figuras meióticas da divisão dos espermatócitos primários para os secundários.

As células de Sertoli (Fig.1.VI) foram caracterizadas por sua irregularidade alongada e com um núcleo de formato arredondado ou piramidal. Estando localizadas perpendicularmente à membrana basal e presentes em todas as fases do ciclo do epitélio seminífero.

\section{Os estádios do ciclo do epitélio seminífero}

Baseado no método da morfologia tubular foi possível identificar as diferentes fases do desenvolvimento das espermátides, notadas nos estádios 1-8. As células predomi- nantes que compõe a associação celular em cada fase e suas características foram as seguintes:

No estádio 1 (Fig.1.I) foi observado a presença de uma geração de espermatogônias do tipo A, espermátides arredondadas, estas com núcleos escuros e evidentes, espermatócitos em paquíteno, estes localizados próximo às espermatogônias e às espermátides arredondadas, e células de Sertoli.

O estádio 2 (Fig.1.II) foi caracterizado pela presença de espermátides com seus núcleos alongando-se em direção ao lúmen do túbulo seminífero, espermatócitos primários em pré-leptóteno e em paquíteno, e as células de Sertoli.

No estádio 3 (Fig.1.III) as espermátides alongadas estavam dispostas em feixes voltados para o lúmen tubular, sendo também observadas espermátides arredondadas dispostas junto aos espermatócitos em paquíteno e diplóteno, espermatócitos em zigóteno, estes observados próximo à lamina basal, além da presença das células de Sertoli.

Duas camadas de espermatócitos em paquíteno e em diplóteno destacaram-se no estádio 4 (Fig.1.IV), além da presença de espermátides alongadas, com feixes mais bem formados que no estádio 3. Uma camada de espermatócitos em zigóteno foi observada próxima à lâmina basal do túbulo seminífero, juntamente com as células de Sertoli. A presença de produtos de meiose foi à característica essencial para a definição deste estádio.

No estádio 5 os feixes de espermátides alongadas e agrupadas estavam bem evidentes, com seus núcleos em direção ao lúmen, as espermatogônias do tipo A, espermatócitos em zigóteno e paquíteno também estavam evidentes. (Fig.1.V).

0 estádio 6 foi caracterizado pela presença de uma evidente camada de espermátides arredondadas, espermatócitos em paquíteno e diplóteno. Os feixes de espermátides alongadas começavam a se desprender em direção ao lúmen. E as células de Sertoli apresentaram-se com formatos característicos e núcleos bem evidentes (Fig.1.VI).

No estádio 7 (Fig.1.VII) do ciclo do epitélio seminífero os tipos celulares observados foram espermátides arredondadas e alongadas, espermatócitos em paquíteno e células de Sertoli. A presença de corpos residuais foi decisiva para a caracterização deste estádio.

0 estádio 8 foi caracterizado principalmente pela maior quantidade de espermatozóides no lúmen tubular em relação aos outros estádios, apresentando também todas as células da linhagem espermatogênica encontradas nos estádios antecedentes, exceto os espermatócitos em zigóteno (Fig.1.VIII).

\section{Frequência dos estádios do ciclo do epitélio seminífero}

As frequências relativas dos estádios do ciclo do epitélio seminífero se encontram descritos nas Figuras $2 \mathrm{e}$ 3. Um total de 200 secções transversais de túbulos seminíferos, sendo os mais arredondados, foi examinado para cada animal. Na primeira variável analisada, animais entre 90 e 150 dias de idade (Fig.2A), os estádios I (24,5\%), IV (14\%), e VIII $(20,5 \%)$ foram os mais observados, enquanto o que apresentou uma menor frequência relativa foi o estádio III $(5,5 \%)$. A segunda variável analisada, de 

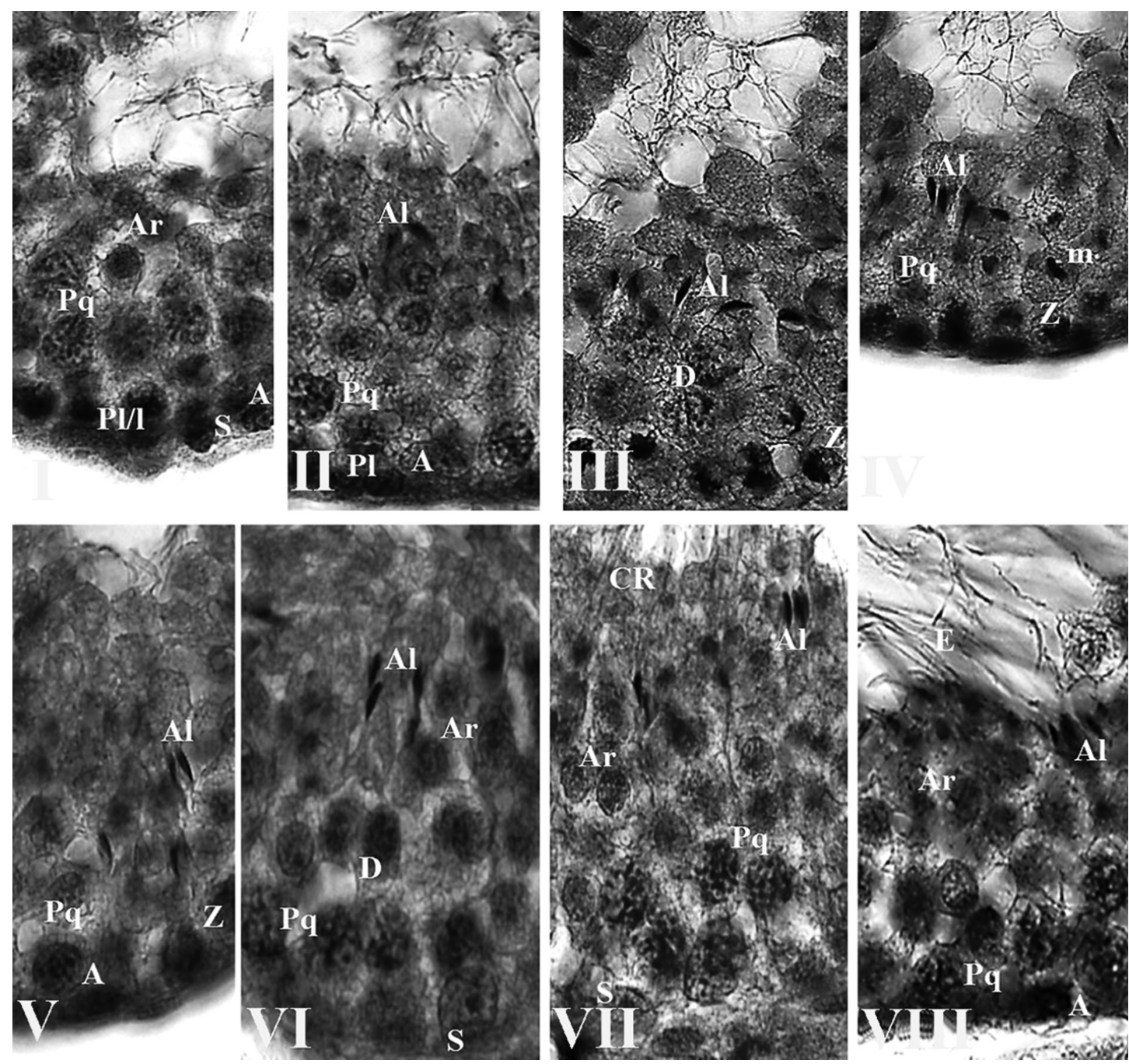

Fig.1. Secções transversais de túbulos seminíferos caracterizando os estádios 1 (I), 2 (II), 3 (III), 4 (IV), 5 (V), 6 (VI), 7 (VII) e 8 (VIII) do ciclo do epitélio seminífero de testículos de preás (Galea spixii) demonstrando os seguintes grupos celulares: [I]: espermatócitos primários em pré-leptóteno/leptóteno (PL/l), espermatócitos primários em paquíteno (PQ) e espermátides arredondadas (Ar); [II]: espermatócitos primários em leptóteno (L), PQ, espermátides em processo de alongamento (Al); [III]: espermatócitos primários em zigóteno (Z), espermatócitos primários em diplóteno (D) e Al em feixes; [IV]: Z, PQ, D, figuras de meiose (m), Ar e feixes de A. [V]: espermatogônias (A), PQ, Ar e Al em feixes; [VI]: $\mathrm{PQ}, \mathrm{Ar}$ e feixes de $\mathrm{Al}$ em direção ao lúmen tubular; [VII]: A, PQ, Ar, A não mais em feixes e próximos ao lúmen, corpos residuais (CR); [VIII]: A, PQ, Ar, Al presentes na borda luminal e espermatozóides no lúmen tubular (E). Todos os estágios apresentaram espermatogônias do tipo A (A) e células de Sertoli (S). Coloração HE, 1000x.
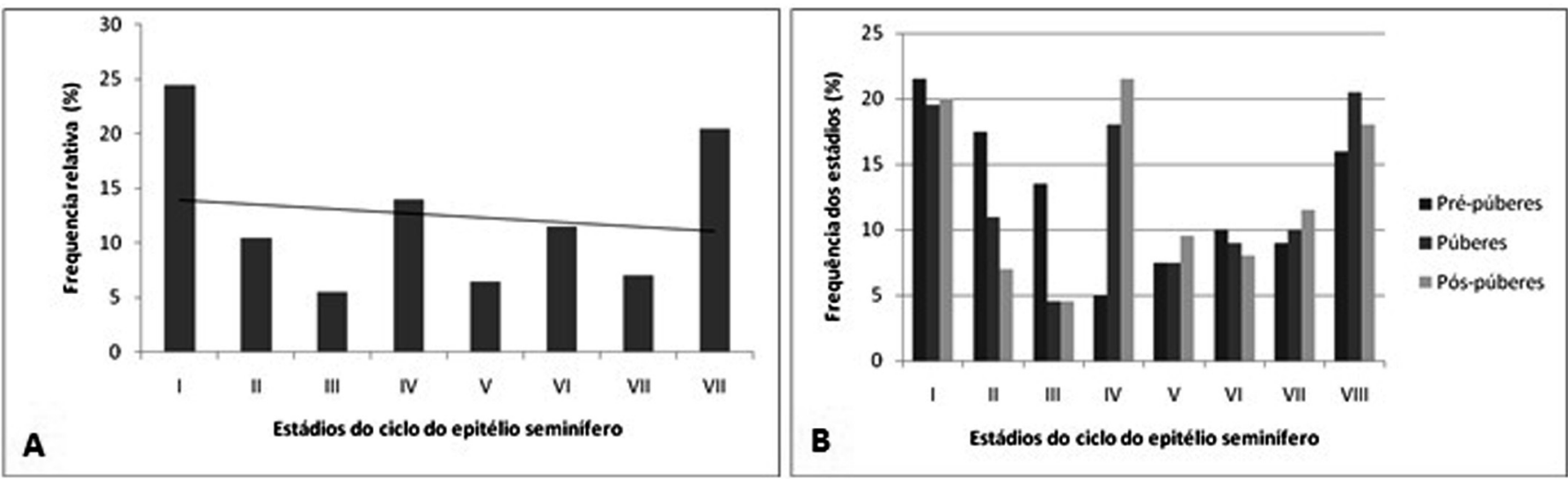

Fig.2. (A) Frequências relativas do ciclo do epitélio seminífero, de animais com idades entre 90 e 150 dias. (B) Frequência relativa dos estádios do ciclo do epitélio seminífero observada nos animais pré-púberes, púberes e pós-púberes. 
acordo com a fase sexual do preá (Fig.2B), foi observado na fase pré-púbere (30 dias) em que os estádios de maior frequência foram os I, II e VII, e o estádio que apresentou menor frequência foi o estádio IV. Semelhante ao que foi observado na fase púbere $(45,60,75$ e 90 dias de idade) e pós-púbere (105, 120 e 150 dias de idade) do preá, em que os estádios predominantes encontrados foram os I, IV e VII, e o estádio com menor frequência nas duas fases foi o III (Fig.2B) . Para a terceira variável estudada, de acordo com a idade do preá $(30,45,60,75,90,105,120$ e 150 dias) o estádio I mostrou-se mais frequente aos 30 dias, o estádio II aos 60 dias, o estádio III aos 30 dias, o estádio IV aos 120 dias, o estádio $V$ apresentou frequências idênticas aos 45, 75 e 150 dias, o estádio VI aos 105 dias, o estádio VII aos 75 dias e o estádio VII aos 90 dias de idade, dados estes apresentados na Figura 3A-H.
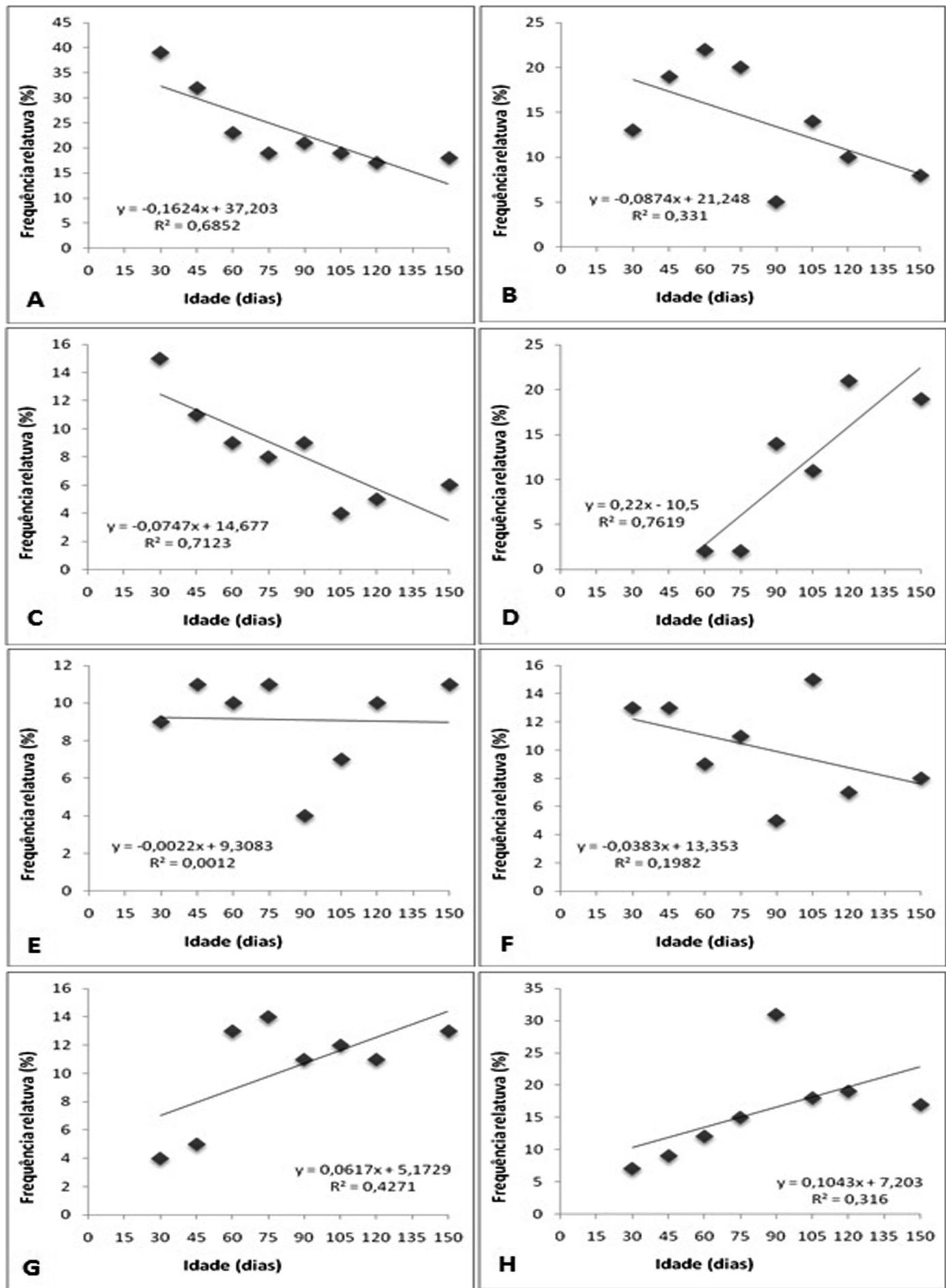

Fig.3. Frequências relativas de cada estádio do ciclo do epitélio seminífero observada nas idades de 30 a 150 dias de idade. (A) Estádio I, (B) estádio II, (C) estádio III, (D) estádio IV, (E) estádio V, (F) estádio VI, (G) estádio VII, (H) estádio VIII. 


\section{DISCUSSÃO}

Os diferentes tipos celulares do epitélio seminífero descritos no preá (Galea spixii) não diferiram daqueles descritos para outras espécies de roedores, tais como a cutia (Assis Neto et al. 2003), rato (Roosen-Runge 1955, Clermont 1972, Parreira \& Cardoso 1991), hamster (Clermont 1954, Oud \& De Rooij 1977), camundongo (Oakberg 1956), cobaia (Clermont 1960) e a capivara (Paula 1999), bem como para outros mamíferos (França 1991, Courot et al. 1970, Clermont 1972). As espermatogônias foram reconhecidas por meio de sua cromatina a qual apresentava semelhança com a das espécies supracitadas, porém o método de coloração utilizado não permitiu a distinção das espermatogônias do tipo A, Intermediárias e do tipo B.

0 epitélio seminífero do preá está constituído pelas células da linhagem espermatogênicas que estão arranjadas em associações definidas no decorrer do processo espermatogênico. Estas associações celulares marcam o ciclo do epitélio seminífero, que de acordo com o método da morfologia tubular, pode ser dividido em oito estádios (Berndtson 1977). 0 sistema acrossômico classifica o ciclo do epitélio seminífero em 14 estádios, sendo este outro método empregado em roedores como o camundongo (Oakberg 1956), hamster (Haaster \& Rooij 1993), rato (Leblond \& Clermont 1952, Hess 1990), porquinho-da-índia (Clermont 1960). A metodologia utilizada nos permitiu a determinação de oito estádios no preá. Sendo observados para tal espécie, assim como para outros mamíferos, associações celulares de apenas um estádio do ciclo em cada corte transversal do túbulo seminífero (Clermont 1963, Swierstra 1968, França 1991, Costa et al. 2004). A composição celular epitelial dos oito estádios foi semelhante ao estudado em ratos (Roosen-Runge \& Giesel 1950), pacas (Pashov \& Matamoros 1984) e suínos por França (1991). As seguintes células da linhagem espermatogênica foram observadas: espermatogônias do tipo A, espermátides arredondadas e alongadas, espermatócitos em paquíteno, pré-leptóteno, diplóteno, zigóteno, espermatogônias, células de Sertoli e Leydig, além também da presença de figuras de meiose e corpos residuais. Entretanto para os preás foi observado que os espermatócitos primários em zigótenos se encontravam nos estádios de dois a cinco, e somente no estádio seis ocorreu a diferenciação para a fase de paquíteno, vindo de encontro ao descrito para catetos por Costa et al (2004).

Em relação à frequência relativa dos estádios do CES do preá, classificados de acordo com a metodologia da morfologia tubular, o estádio I apresentou-se mais frequente em animais entre 90 e 150 dias de idade e o III apresentou-se em menor frequência. Pashov \& Matamoros (1984) observaram que para as pacas os estádios de maior frequência foram o I e II, já em contrapartida o estádio VI foi o menos frequente, deferindo de camundongos (Pires 2011) os quais apresentaram maior freqüência para os estádios VII e VIII e menor freqüência para os estádios I e II. Contudo, uma variação na frequência relativa dos estádios do ciclo do epitélio seminífero representa uma maior distancia filogenética entre as espécies de roedores.
Agradecimentos.- À Fundação de Amparo e Pesquisa do Estado de São Paulo (FAPESP Proc.2009/51718-3) pelo apoio financeiro para a realização deste estudo e ao Centro de Multiplicação de Animais Silvestres da Universidade Rural do Semi Árido (UFERSA-RN) por terem cedido os animais utilizados nesta pesquisa.

\section{RFERÊNCIAS}

Amann R.P. \& Schanbacher B.D. 1983. Physiology of male reproduction. J. Anim. Sci. 57(S2):380-403.

Assis Neto A.C., Carvalho M.AM, Melo, M.I.V., Miglino M.A., Oliveira M.F. \& Mariana A.N.B. 2003. Fases do desenvolvimento e diferenciação testicular em cutias (Dasyprocta aguti) criadas em cativeiros. Braz. J. Vet. Res. Anim. Sci. 40:71-79.

Berndtson W.E. 1977. Methods for quantifying mammalian spermatogenesis: a review. J. Anim. Sci. 44(5): 818-83.

Clermont Y. 1954. Cycle de l'épithelium seminal et mode de renouvellement des spermatogonies chez le hamster. Revue Canad. Biol. 13:208245.

Clermont Y. 1960. Cycle of the seminiferous epithelium of the guinea pig: a method for identification of the stages. Fertil. Steril. 11: 563-573.

Clermont Y. 1963. The cycle of the seminiferous epithelium in man. Am. J. Anat. 112:35-51.

Clermont Y. 1972. Kinetics of spermatogenesis in mammals: seminiferous epithelium cycle and spermatogonial renewal. Physiol. Rev. 52(1):198-236.

Costa D.S., Henry M. \& Paula T.A.R. 2004. Espermatogênese em catetos (Tayassu tajacu). Arq. Bras. Med. Vet. Zootec. 56(1):46-51.

Courot M., Hochereaua-de-Reviers M.T. \& Ortavant R. 1970.Spermatogenesis, p.339-432. In: Johnson A.D., Gomes W.R. \& Vandemark N.L. (Eds), The Testis. Vol.1. Academic Press, New York.

Curtis S.K. \& Amann R.P. 1981. Testicular development and establishment of spermatogenesis in Holstein Bull. J. Anim. Sci. 53:1645-1657.

Eisenberg J.F. \& Rerdford K.H. 1999. Mammals of the Neotropics: the Central Neotropics, Ecuador, Peru, Bolivia, Brazil. Vol.3. University of Chicago Press, Chicago. 609p.

França L.R. 1991. Análise morfofuncional da espermatogênese de suínos adultos da raça Piau. Tese de Doutorado, Universidade Federal de Minas Gerais, Belo Horizonte. 185p.

França L.R. \& Cardoso F.M. 1988. Desenvolvimento testicular de suíno. II. Análise histométrica. Arq. Bras. Med. Vet. Zootec. 40(3):181-192.

França L.R. \& Russell L.D. 1998. The testis of domestic animals, p.197-219. In: Regadera J. \& Martinez-Garcia F. (Eds), Male Reproduction: a multidisciplinary overview. Churchill Livingstone, Madrid.

Guerra M.O. 1983. Comparação entre dois métodos de determinação da frequência relativa dos estádios do ciclo do epitpelio seminífero, em dados da literatura. Revta Bras. Biologia 43(4):385-394.

Haaster L.H. \& Rooij D.G. 1993. Spermatogenesis is accelerated in the immature Djungarian and Chinese hamster and rat. Biol. Reprod. 49:12291235.

Heller C.G. \& Clermont Y. 1964. Kinetics of the germinal epithelium in man. Recent Progr. Horm. Res. 20:545-571.

Hess R.A., Schaeffer D.J., Eroschenko V.P. \& Keen J.E. 1990. Frequency of the stages in the cycle of the seminiferous epithelium in the rat. Biol. Reprod. 43:517-524.

Leblond C.P. \& Clermont Y. 1952. Definition of the stages of the cycle of the seminiferous epithelium in the rat. Ann. N.Y. Acad. Sci. 55:548-584.

Luna L.G. 1968. Manual of Histology Staining Methods of the Armed Forces Institute of Pathology. $3^{\text {rd }}$ ed. McGraw-Hill, p.197-219.

Mendes B.V. 1987. Plantas e Animais para o Nordeste. Ed. Globo, Rio de Janeiro. $167 \mathrm{p}$.

Oakberg E.F. 1956. Duration of spermatogenesis in the mouse and timing of stages of the cycle of the seminiferous epithelium. Am. J. Anat. 99:507-516.

Oliveira M.F., Mess A., Ambrósio C.E., Dantas A.G., Favaron P.O. \& Miglino M.A. 2008. Chorioallantoic placentation in Galea spixii (Rodentia, Cavio- 
morpha, Caviidae). Reprod. Biol. Endocrinol. 6:39. doi: 10.1186/14777827-6-39.

Oliveira G.B., Rodrigues M.N., Sousa E.S., Albuquerque J.F.G., Moura C.E.B., Ambrósio C.E., Miglino M.A. \& Oliveira M.F. 2010. Origem e distribuição dos nervos isquiáticos do preá. Ciencia Rural 40:8, 1741-1745.

Ortavant R., Courot M. \& Hochereau-de-Reviers M.T. 1977. Spermatogenesis in domestic mammals, p.203-227. In: Coole H.H. \& Cupps P.T. (Eds), Reproduction in Domestic Animals. Academic Press, New York.

Oud J.L. \& De Rooij D.G. 1977. Spermatogenesis in the Chinese hamster. Anat. Record 187:113-124.

Parreira G.G. \& Cardoso F.M. 1991. Reproductive biology of males Bolomys lasiurus Lund, 1841 (Rodentia, Cricetidae). I. Morphology of spermatogenesis and seminiferous epithelium. Revta Bras. Biologia 51(3):639-46.

Pashov B. \& Matamoros Y. 1984. Description histological del epitélio seminifero del testiculo del tepezcuinte (Cuniculus paca Brisson, 1962) e identificación de sus diferentes etapas. Cienc. Vet. 1(6):9-15.

Paula T.A.R. 1999. Análise histométrica e funcional do testículo de capivara (Hydrochoerus hydrochaeris) adulta. Tese de Doutorado em Biologia Celular, Universidade Federal de Minas Gerais, Belo Horizonte, MG. 84p.

Pires A. 2011. Pre-and postnatal exposure to ambient levels of urban particulate matter $(\mathrm{PM} 2,5)$ affects mice spermatogenesis. Inhal. Toxicol. 23:237-245.
R Development Core Team 2006. R: A language and environment for statistical computing. R Foundation for Statistical Computing, Vienna, Austria. ISBN 3-900051-07-0, URL http://www.R-project.org

Reis N.R., Peracchi A.L., Pedro W.A. \& Lima I.P. 2006. Mamiferos do Brasil. Editora da Universidade Estadual de Londrina, Londrina. 437p.

Roosen-Runge E.C. 1955. Untersuchungen über die Degeneration samenbildender Zellen in der normalen Spermatogenese der Ratte. Zellforsch. Mikrosk. Anat. 41:221-235.

Roosen-Runge E.C. \& Giesel Jr O. 1950. Quantitative studies on spermatogenesis in the albino rat. Am. J. Anat. 87(1):1-30.

Russell L.D., Ettlin R.A., Sinha-Hikim A.P. \& Clegg, E.D. 1990. Histological and Histopathological Evaluation of the Testis. Cache River Press, Clearwater, Florida. 286p

Sharpe R.M. 1994. Regulation of spermatogenesis, p.1363-1434. In: Knobil E. \& Neil J.D. (Eds), The Physiology of Reproduction. $2^{\text {nd }}$ ed. Raven Press, New York.

Smithwick E.B., Young L.G. \& Gould K.G. 1996. Duration of spermatogenesis and relative frequency of each stage in the seminiferous epithelial cycle of the chimpanzee. Tissue and Cell 28(3):357-366.

Swierstra E.E. 1968. Cytology and duration of the cycle of the seminiferous epithelium of the boar: duration of spermatozoan transit through the epididymis. Anat. Rec. 161:171-186. 